\title{
7. Native title and the Torres Strait: encompassment and recognition in the Central Islands
}

\section{Julie Lahn}

It seems that contemporary perspectives on native title have shifted rather dramatically from the early optimism that saw the Mabo decision described as a 'moral and historical statement of truth [that provides] the strongest justification yet for the claims of those dispossessed', potentially even challenging (or at least problematising) settler sovereignty itself (Pearson 1993: 82). Former director of the Northern Land Council, Mick Dodson, has described native title as providing relatively few benefits for Aboriginal people, and as forming part of a process of 'further dispossession'. ${ }^{1}$ In a recent address he described the Native Title Act 1993 (Cwlth) (NTA) and its amendments as embodying a racist doctrine of native title extinguishment (Dodson 2007).

One of the most forceful critiques along these lines has been that provided by Wolfe (1999), who argues that the principal function of native title is 'paradoxically as much to provide grounds for delimiting indigenous relations to land as for their recognition' (1999: 203). Put differently, to accept the terms of recognition within which the notion of 'native title' is framed is to endorse the terms for its extinguishment as well as the radical assumption of sovereignty upon which both are based. This view is a compelling one; the Mabo decision, the NTA (and associated legislation) and the growing corpus of native title case law, together certainly embody the power that defines sovereignty-the arrogation of authority to set the ultimate terms of exclusion and recognition, to delineate the space of rights and non-rights (see also Agamben 1998). And in this sense it is certainly possible to contend that native title is as much implicated in the continuing dynamics of colonisation as it can ameliorate aspects of it.

This theme is elaborated by Morris (2003), where he argues that the various determinations under the NTA have done more to limit and extinguish Indigenous claims to land than to facilitate them. He describes the original High Court Mabo determination as 'essentially perverse' in that it 'did not concede, the right to indigenous communities to exercise traditional law and customs over their lands - and nor could it without undermining its own authority' (2003: 140). At the same time, the decision enshrined a 'continuation of traditionalism' as the basis of native title claims, where 'indigenous identity and

\footnotetext{
1 Mick Dodson in conversation, Awaye! ABC Radio National, 10 February 2006.
} 
culture must put itself through a trial, and demonstrate its members' authenticity' (2003: 140).

Aspects of the limits of native title are now well-rehearsed among anthropologists, though their critical observations have usually been both less trenchant and less political. Among the most prescient early commentators were Kondos and Cowlishaw (1995), who drew attention to the potential for native title to reify notions of tradition, while Merlan (also in 1995), pointed to the risk for a 'regimentation' of customary practices. A closely related concern seeks to problematise any stress on systematicity in native title at the expense of contingency and reflexivity (Weiner 2000). These views in some respects parallel Wolfe's notion of 'repressive authenticity', where native title is depicted as displacing the 'burden of history' from 'the fact of expropriation to the character of the expropriated' (1999: 202).

But anthropologists have often also maintained an interest in exploring the transformative cultural and social potential in the arena of native title. Weiner (2003), for example, writes against the grain of a 'space of recognition' perspective of native title (see Smith, Chapter 6) in arguing for a more complex anthropological engagement with native title processes themselves as a 'total social fact', with productive potential in terms of the cultural and social practices of an indigenous population that has a long history of 'conjunctural engagement' with Euro-Australian institutional practices. At the same time, Weiner acknowledges the danger of an overall diminution in what the public and the legal establishment acknowledge as the 'total condition of recognisable Aboriginality in Australia' (Weiner 2003: 103).

In what is an excerpt from a larger study (Lahn 2003), I want to reflect on a similar question, that of the relation of native title to the total condition of recognisable indigeneity in Australia (rather than Aboriginality), with a specific focus on the Central Islands of the Torres Strait. As Keen (1999: 2) points out, indigeneity is an a priori interpretive concept within native title. I argue here that multiple forms of indigeneity are acknowledged among Torres Strait Islanders. I focus on the two contrasting modes with which I am most familiar, and which form a key distinction Islanders themselves draw in the Central Islands: that of being a 'native' or a 'foreigner'. It is important to note that both these terms refer to people recognised in local terms as Torres Strait Islanders. But they are differentiated in the Central Islands as distinct states of being indigenous. It is equally important to stress that neither term is pejorative; in fact, the descriptive 'foreigner' has generally been associated with a degree of status in the Central Islands. Both labels are used for self-description (as well as ascription) though they are not expressions that appear in everyday interactions.

This situation is a difficult one to render in English, which lacks adequate means to characterise such a contrast in a way that still affirms an embracing state of 
indigeneity. It could be helpful perhaps to return to one of the specific etymological significances of the term 'autochthony', which involves the notion of 'arising in situ' (i.e. rather than arriving from elsewhere). In this sense, the labels of native and foreigner in the Central Islands could be understood as drawing a distinction between 'indigenous autochthons' and 'indigenous non-autochthons' ${ }^{2}$ But such an approach is limited by the degree to which the term indigenous has come to be regarded among English-speakers as synonymous with the term autochthonous - to all intents and purposes, an indigene is regarded as an autochthon. With this difficulty in mind, I will utilise the Torres Strait Creole terms neitiv (native) and porena (foreigner) for the remainder of the discussion. While still somewhat recognisable to English speakers, their clear difference from their English cognates serves as a reminder that the terms do not bear the same conceptual baggage.

My intention here is to briefly explore the meeting between this neitiv/porena identification in the Central Islands and the representational requirements of native title. I argue that native title's regime of value marginalised, and potentially stigmatised this kind of local identificatory distinction. My focus is Warraber Island, the southernmost of the Central Island group. I have been working there since 1996, conducting doctoral fieldwork and native title research. Warraber people first represented themselves as a claimant group within a claim based on the Torres Strait Islander Land Act 1991 (Qld) (TSILA); shifts in representation occurred in engaging with the different demands of native title. ${ }^{3}$ These shifts illustrate aspects both of the unequal social relations inherent in the representational demands of native title as a state-sponsored regime of recognition, and of the capacity of local people to respond creatively to such demands.

\section{Neitiv ('native') and porena ('foreigner')}

Warraber residents use the neitiv/porena terminological division both when discussing their ancestors, and in expressing contemporary forms of local identity. It forms a profoundly significant expression both in their understanding of the past, and in their perception of their contemporary community. The primary significance of the neitiv/porena distinction involves a view that neitiv figures were present in the islands before the sudden influx of various foreigners or outsiders (ausaid man) into the Torres Strait from the mid-nineteenth century.

2 This kind of a distinction is widespread throughout insular Southeast Asia, where indigenous groups - sharing a single distinct language and name - frequently distinguish within themselves descent from autochthonous and non-autochthonous ancestors. Where this occurs, specific realms of authority have often been historically divided according to this status, for example ritual leadership (often linked to local fertility) associated with autochthons, and secular community leadership with the 'outsiders' or non-autochthons. I thank Phillip Winn for drawing this parallel to my attention.

3 I observed the TSILA proceedings while conducting doctoral fieldwork at Warraber and later became a participant in their native title claim as the anthropologist compiling the 'connection report'. 
This occurred as part of the arrival of European marine industries to the region, which brought with them a labour force composed predominantly of Pacific Islanders, though with a number of Europeans in supervisory roles (see Beckett 1977, 1987; Mullins 1990, 1995; Shnukal 1992a, 1992b, 1995). ${ }^{4}$ Pacific Islands of origin included Vanuatu, Samoa, Fiji and New Caledonia.

Some of the Pacific Islanders remained in the Torres Strait, marrying local Torres Strait women and producing children. The influence of these Pacific Islander residents and their descendants is especially marked in the Central Islands, which formed a key centre of marine industry activity. Aspects of Pacific Island music and dance forms, for example, have become a thorough part of contemporary Torres Strait Islander performance (see Lahn 2004; Lawrence 2004). Crucially, and as a result largely of colonial systems of racial classification, Pacific Islanders not only held superior positions in the marine workforce but generally served as intermediaries between Europeans and Torres Strait Islanders in various capacities, including Christian missionising activity. A legacy of this role was that the Pacific Islanders and their descendants, now referred to as porena, were regarded by local people as possessing special abilities - in particular the skills necessary to interact effectively with Europeans and European institutions (and, as a consequence, to buffer locals from the demands of these spheres). ${ }^{5}$ Porena people in the Central Islands still dominate such quasi-governing bodies as Island Councils, and are regarded by neitiv residents as well-suited by their ancestry for playing such a role.

In fact, all Warraberans can potentially trace some form of genealogical connection to both neitiv and porena ancestors. The basis of contemporary identification as neitiv or porena relates to the status of male apical ancestors. Among Warraberans, as with other Central Island populations, there is a pronounced patrilineal emphasis in local thinking about descent. Female ancestors tend to be marginalised by comparison to their male counterparts; when Warraber people describe their personal lineage, as few females as necessary will be included in tracing connections to a male apical ancestor. Wherever possible, a patrilineage will be traced (or as near to a patrilineage as practicable). This parallels a general predisposition to depict men as the most active and influential social agents. All narratives concerned with historical events stress male

\footnotetext{
${ }^{4}$ The notion of 'foreigners' is not exclusive to Warraber. In the Eastern Islands, for example, the term nog le ('outside men') is used to designate 'foreigners' or 'outsiders' (Shnukal 1992a: 13) in much the same way that porena is used on Warraber. Interestingly, the Meriam used the term salmis to refer to Pacific Islanders and the term nog le was used to refer to other Torres Strait Islanders who were excluded from the Malo-Bomai cult (Jeremy Beckett pers. comm. 2004).

5 Another factor in the rise to prominence of porena in the Central Islands, and likely a critical one, involved significant declines in local populations there (as elsewhere in the Torres Strait) linked to a combination of factors but particularly successive waves of epidemic disease. These were most serious in the latter half of the nineteenth century, but continued into the early decades of the twentieth century (Mullins 1995).
} 
ancestors, in particular the part played by exceptional and powerful men. ${ }^{6}$ The role of women is generally overlooked or disregarded.

Those able to trace descent in this way from male apical ancestors who were porena are those who consider themselves today as also being porena. The most important and earliest of these ancestors for Warraber people is an individual from Vanuatu named Bubarei. Similarly, those who trace descent from a male apical ancestor who was neitiv (i.e. someone deemed present in the islands before the outsider influx) consider themselves to be neitiv. A large majority of Warraber residents do not possess any male neitiv ancestors. They describe their descent wholly in terms of male porena figures, rather than including female neitiv ancestors with whom they could assert a connection. Therefore, the majority segment of Warraber's contemporary population represent themselves as porena.

The key factor in categorising significant personal ancestors in terms of a neitiv/porena contrast involves their presence on Warraber before or after the arrival of the marine industries. It is engendered by temporal association rather than ideas about ultimate origin. For Warraber people, this in turn generates further multifaceted associations that give rise to particular discourses of value. The first might be called the neitiv's 'power of precedence'. By pre-dating the arrival of others, neitiv figures are recognised both as being the original local landholders and also as possessing an intimate relation to locality, manifest in their close relation to particular significant sites in the landscape (some of which are associated with the fertility and productivity of island resources, such as the wongai fruit - a pre-colonial staple that retains symbolic importance). Porena ancestors are instead valorised as being 'agents of change', linked to what is regarded as a generally positive historical transformation of pre-existing life on Warraber Island. In this respect, for the wholly Christian Warraber population, the arrival of the marine industry is inextricably entwined with the arrival of Christianity. As noted, Pacific Islanders were prominently involved in both, as missionaries and as boat crew and owners (Lahn 2003). ${ }^{7}$

Importantly, while both valorising discourses coexist in Warraber society, they cannot be said to convey equal contemporary status or prestige on the two sections of the population. There are very few contexts where the power of precedence' asserted by the minority neitiv-identifying population is relevant, and to date, it has not provided a basis for eminence or influence in the Warraber community. By contrast, porena descendants, the majority population, have monopolised positions of formal and informal authority for some period on the island. During the involvement of Warraber and Poruma populations in NTA

\footnotetext{
6 This tendency of prevailing gender norms to shape historical accounts has been highlighted elsewhere in the Torres Strait (for example Davis 1998).

7 Jeremy Beckett (pers. comm. 2004) suggests that the position of Pacific Islanders in marine industries played a more critical role in their local prominence than involvement in the activities of the London Missionary Society. See Lahn (2004) for a discussion on the arrival of Christianity to the Torres Strait.
} 
claim processes, issues of the contemporary significance of neitiv and porena ancestry re-emerged in potentially novel ways. But it is necessary first to trace the mode of collective representation that Warraberans developed in response to a first wave of land claims under the TSILA.

\section{The Torres Strait Islander Land Act and the Gau Clan}

Before engaging with native title, Warraber Islanders pursued a successful claim using the TSILA. This Act establishes procedures by which Torres Strait Islanders can make application to the Queensland state government to claim lands designated as 'transferable'. ${ }^{8}$ Between 1996 and 1998 Warraber residents pursued a claim under this legislation over five uninhabited nearby islands: Yarpar (Roberts), Ullu (Saddle), Bara (Bet), Guiya (Poll) and Aurid (recorded by Haddon (1935) as Yaywad). These islands were regularly visited by Warraber and Poruma people, though none had permanent residents. In the past some of these islands had also been used in intermittent gardening and camping, largely linked to movements in marine industry activities.

The TSILA claim was lodged on grounds of 'customary affiliation'. 9 The legislative terms delineating this basis for establishing a land claim state that the Land Tribunal assessing the claim must be:

satisfied that the Torres Strait Islander has a connection, or that members of the group have a common connection, with the land based on spiritual or other associations with, rights in relation to, and responsibilities for, the area of land under Island Custom. ${ }^{10}$

Clearly, this approach to customary affiliation is quite broad in scope. Particular core terms (for example 'connection', 'associations', 'responsibilities') are not specifically defined. Instead, there is repeated recourse to 'Island custom', which is presumed a priori to elucidate such concepts. The TSILA offers the following definition of Island custom:

Island custom, known in the Torres Strait as Ailan Kastom, is the body of customs, traditions, observances and beliefs of Torres Strait Islanders generally or of a particular group of Torres Strait Islanders, and includes any such customs, traditions, observances and beliefs relating to particular persons, areas, objects or relationships. ${ }^{11}$

As a result, the terms of TSILA have a rather encompassing and inclusive tenor, notwithstanding its design as an alternative to native title (and notable limitations

\footnotetext{
8 These include Deed of Grant in Trust (DOGIT) lands, reserve lands, and crown lands deemed available for transfer (see Brennan 1991 and Malbon 1996 for a discussion of DOGIT lands in relation to TSILA).

9 'Customary affiliation' is one of three bases through which a claim under TSILA may be lodged. The others are 'historical association' and 'economic or cultural viability' (TSILA s. 50-57).

10 TSILA s. 50 (1)

11 TSILA s. 8.
} 
in the forms of tenure it makes available to successful claimants). Indeed, this appears to have formed an aspect of the policy intentions of the government of the day. For example, the phrase 'spiritual or other associations' in the first passage cited above originally read 'spiritual and other associations' (as it does in the equivalent Queensland Aboriginal Land Act 1991). The alteration was explained in parliament by the then Queensland Minister for Family Services and Aboriginal and Islander Affairs:

The Torres Strait Islander Land Act will also be amended to ensure that the basis upon which land is claimed in the Torres Strait appropriately reflects islander relationships with land. I am advised that the principles of traditional affiliation with land in accordance with Torres Strait Islander custom may not necessarily include a notion of spiritual association with land. Consequently, the definition of traditional affiliation will permit but not require a claimant to demonstrate a spiritual relationship with the land (Warner 1991, cited in Neate 1997: 14).

The claim itself takes the form of an application of transfer, essentially an administrative rather than judicial process. ${ }^{12}$

In the case of the Warraber claim, an entity known as the Gau Clan formed the claimant group. The Gau Clan derives its local coherence from visions of the Vanuatuan ancestor figure of Bubarei. Bubarei is the earliest known outsider to father children on Warraber Island with an Islander woman named Wawa (who resided on Warraber, but whose own origins were in fact from a different island in the Torres Strait). Their 10 children formed the first generation of porena Warraberans, who were provided with land by neitiv landholders at that time, and hence incorporated by custom into Warraber's population. As the earliest known porena male ancestor, and as a prolific progenitor, Bubarei is a figure to whom all residents of Warraber in fact possess traceable genealogical links. The Gau Clan is not, then, a 'clan' in the classic anthropological sense; membership is not limited to descent but can be asserted on the basis of any combination of consanguineal or affinal connection to any of Bubarei's descendants. In this way the Gau Clan was able to encompass the entire population of Warraber (who are all in fact related in some sense) while simultaneously stressing the majority status of the porena population and the special regard given to porena historical figures.

\footnotetext{
12 Essentially, there is an investigation by the Department of Natural Resources, aided by a consultant employed by the applicant/s. Its focus concerns the identity of the persons making the application and the grounds on which the application is being made. Consultation takes place with those people designated as 'particularly concerned with the land' subject to the transfer claim. Under the Act, this includes people who are connected to the land by 'Island Custom'; who live on or use the land; or live on or use neighbouring land (State of Queensland 2000: 2). Once these consultations are complete, a Land Tribunal established under the TSILA arrives at a decision and makes a recommendation to the relevant Queensland Minister. The Minister must grant approval for a transfer to occur.
} 
Clans, and their associated totems, were not part of everyday discourse at Warraber during my period on the island, nor did they play any role in shaping social relations. Once reputedly critical in defining marriageability, kinship has long displaced clanship in this role (an observation Haddon makes in reference to the Western Islands as early as 1904 (1904: 160-1). Sugimoto (1983: 92), who conducted brief fieldwork on Warraber in the 1970s, noted that 'the totem clans seem to have played an important role in village life before the advent of Christianity, but they are hardly functioning now.' Intent on linking local patronyms to specific totemic clans, Sugimoto remains ambiguous as to what these residual functions may have been. He described eight totems as extant among Warraberans; some 25 years later I could identify only two-gau (associated with poren people, as described) and womer (linked to neitiv identity). ${ }^{13}$

However varied the presence, meaning and contemporary relevance of totems and clans throughout the region, Warraber people have been aware for decades of the role of totemic clans as identificatory categories associated with territorial interests in island communities in the Torres Strait. As a vehicle for representing the Warraber population as a whole in the context of the TSILA claim, the emergence of the Gau Clan can certainly be seen in terms of the dynamics of objectification discussed by Glaskin (Chapter 3), where self-conscious definitions of culture are fostered that may have an important role in internal group definition and reproduction. Totemic symbols and clan names are now undergoing something of a contemporary renaissance in the Torres Strait, appearing on gravestones and in the speeches associated with tombstone unveilings - an iconic event within 'Torres Strait Islander culture'.

In the context of Meriam people and the revitalisation of the Malu-Bomai cult, Beckett (1995: 30) has discussed the capacity for cultural reflexivity and objectification in the Torres Strait, the development of what he terms a 'relativistic view' of their own culture by the Meriam, influenced in part by their reading of Haddon. He also suggests that renewed interest in the cult would have been unlikely had it not resonated with the contemporary life of Meriam people, and points to the 'sensuous everyday experience' (1995: 30) of presence on Mer Island as pivotal in this regard.

Importantly, local discourse surrounding the Gau Clan on Warraber stressed its ability to reflect locally salient notions of social relatedness that are rooted in the idioms of Christianity and kinship. This is most aptly expressed in the local phrase 'ol wan pamli' ('all one family'), which communicates an ethical sensibility

13 Other totems are certainly present on Warraber in association with residents originating on other islands; for example, Mabuiag. According to Sugimoto (1983), Warraber totems in addition to gau and wamer [sic] were: dangal (dugong), ger (marine snake), kadal (crocodile), kuzi (eagle), baidam (shark), umai (dog), and samu/emu (cassowary or emu). 
linked to idealised notions of island community and sociality. The Gau Clan, as a representational vehicle, was able to reflect these overt values in embodying an inclusive and seamless group of landholders, undifferentiated by local neitiv/poren distinctions. In this sense the Gau Clan effectively represented Warraber as a community of co-residents, with equal rights in land, given additional coherence and moral content through residents' collective identification as Christians. In other words, existing 'representational flows' (Merlan 1998: 180), which in this case included those of Torres Strait and Australian ideas concerning indigeneity as well as local understandings of Christianity, were engaged by local people themselves to produce images partaking of the past but also expressing and satisfying contemporary sensibilities.

\section{Native title}

In 1999, the year following the success of the TSILA claim, Warraber residents initiated a native title claim over Warraber and surrounding islands. The NTA demanded a demonstration of emplaced social identity that was subject to much more sharply delimited terms of authenticity and legitimacy than was the case in the TSILA. In particular, the native title process embodies a regime of value that valorises specific forms of continuity with the pre-colonial past.

Warraber people were well aware of the Mabo decision and approved of the idea that this involved the Australian nation recognising Islander possession of Torres Strait islands. However, they also generally considered the 'hand-over' ceremony under TSILA in 1998 as being akin to the Mabo outcome. The central issue that created interest among Warraber people in pursuing a native title claim was the gradual realisation that the TSILA land transfer did not actually include Warraber Island itself, but focused solely on surrounding, uninhabited islands. While some residents already knew this, many clearly did not until this was raised in information provided by the Torres Strait Regional Authority (TSRA), the native title representative body for much of Torres Strait.

In 1999 I was engaged by the TSRA to compile a Connection Report (CR) as part of a Warraber native title application covering the terrestrial areas of Warraber, Bara, Guiya, Buboi, Ullu, Ugain, Miggi Maituin, and Dugong islands. Senior staff in the TSRA's Native Title Office acknowledged that the CR criteria and associated research activities were limited in scope and/or complexity, certainly falling short of anthropological-style explanation. Nevertheless, they sought to address the requirements as fully as possible for the purposes of pursuing a negotiated settlement on behalf of the claimants in the most straightforward manner. To this end, the TSRA research brief followed the preferred structure and guidelines provided by the Queensland government. Some elaboration and interpretations of native title case law at that time were also offered as additional thematic foci in the research task. These included now familiar elements: detailing 
principles of group membership, genealogical information linking the claimant group to people who possessed the area before annexation, and with respect particularly to the criteria of rights and interests, descriptions of 'coherent social structure' and 'cultural logic' deriving from sources independent of relations with the colonial regime. There was an awareness that the CR could be called into evidence were this or other related claims to be contested in court at a future time.

In many respects, evidence in support of the native title claim appeared relatively straightforward. Identifiable Warraber ancestors were present on the island at annexation in 1872; land ownership is vested in Warraberan families and individuals who together formed the claimant group and who regularly engaged in local negotiations over the use of their own and others' land. Many of the documented social and cultural practices in which their ancestors were engaged (e.g. gathering marine resources, performing certain rites) remained in evidence in the contemporary period.

But a fundamental problem emerged concerning residents' orientation to group identification and ancestry as expressed through the Gau Clan. As discussed, the apical ancestor of the Gau Clan - Bubarei - was not a Torres Strait Islander. And while his children were gifted land according to local custom, Bubarei was not. He remained an outsider; in local terms, he is not considered to have been 'made a brother' by local people (i.e. incorporated by island custom). Indeed, he was reputedly not welcome at Warraber Island, and never resided there.

The Gau Clan, as a collectivity that exists essentially in reference to Bubarei, potentially infringe core requirements for native title, at least as it has come to be defined through the CR process, in turn drawing on a priori conceptualisations of indigeneity. As both a non-Islander and a non-Warraberan, Bubarei did not provide a suitable foundation for 'identification of a [relevant, indigenous] claimant group' (Department of Premier and Cabinet 1999). As someone who was never provided with land on the island, and did not reside there, Bubarei possessed no 'rights and interests in the territory claimed, which must derive from traditional law and custom' nor could he represent a source of 'continuous connection, that is, between claimant group and claimed area from a time before annexation' (Department of Premier and Cabinet 1999). Bubarei's Warraber-based children were certainly able to be regarded as indigenous to the Torres Strait under the terms of the NTA (as they were under TSILA) on the basis of their mother's status, that is of Bubarei's Torres Strait Islander spouse Wawa. However, native title required that Warraber claimants demonstrated descent from land-holding pre-colonial ancestors, that is, from neitiv figures, not from an outsider like Bubarei, a fact that rendered the Gau Clan irrelevant under the NTA. 


\section{Warraberalgal}

In effect, the demands of indigeneity under native title offered recognition to only one set of Warraber ancestors, those who were neitiv. The native title process elevated the prominence of these figures over porena ancestors - a reverse of the existing local situation. In addition, the genealogical links that it was necessary to document among Warraberans involved tracing links to a range of neitiv ancestors who were largely female. I asked residents how they would refer to a group thus defined (in Torres Strait Creole). The consistent response was 'Warraber people' - the discourse of totemic clans was subverted in this new framing. I asked how this concept would be expressed in prapa tok or langus (i.e. in the Kulkalgaw Ya language). The answer was Warraberalgal, meaning 'people belonging to Warraber'. This became the name of the native title claimant group.

Elicited from Warraber people themselves, the term Warraberalgal was certainly an apt illustration of the importance of place within local representations of collective identification, but clearly marked a shift from the Gau Clan, with its emphasis on poren ancestors esteemed by the bulk of Warraber's residents. Both male and female informants on Warraber struggled to reconcile their sentiment of male ancestral value with the state's valorising of a definition of continuity and connection that marginalised many of these same figures. They fully comprehended the requirements placed before them, but those with porena male ancestors in particular were dissatisfied by a requirement to shift the existing local emphasis in matters of descent in order to secure native title to an island they already occupied and considered theirs. It especially rankled that the State of Queensland had already transferred other islands to them in the previous year as the Gau Clan, a collective form of representation that was successful without recourse to female or neitiv ancestors.

Far more than the Gau Clan, Warraberalgal marked an instance not simply of cultural objectification, but of native title as a realm of intercultural production - a form of representation occupying a discursive ground where a regime of value imposed by the nation-state intersects with the existing reality of an indigenous population. In this sense it belongs wholly to neither, but is inseparable from both. ${ }^{14}$ For the state, a conception of 'native title' that relies very much on precursive cultural assumptions concerning an authentic indigeneity couched in terms of autocthony requires descent-based continuity of physical occupation. For most Warraberans, a valorised identification with apical male ancestors takes preference over visions of absolute ancestral emplacement. It is imperative to note that the outcome of such a meeting is an

\footnotetext{
14 See the edited volume by Hinkson and Smith (2005) for explorations of the 'intercultural' in Aboriginal contexts.
} 
expression of unequal social relations - as is native title itself (Merlan 1998: $176,181)$.

But while it is fair to state that, as a point of personal or collective identification, the new basis of group boundedness for the NTA claim was far less intuitively meaningful, it is notable that the new claimant group emerged as being just as embracing and inclusive as the Gau Clan had been. In this sense the level of 'violence' involved in the form of recognition offered to Warraber people by native title (see Smith, Chapter 6) could be described as somewhat muted.

\section{Reflections}

That the term 'native' featured in the expression 'native title' was not lost on some Warraberans. Initially, those persons who regarded themselves as neitiv asked me privately if the claim related specifically to them; that is, if they were the 'natives' being referred to in 'native title'. However, as the importance of female neitiv ancestors among poren residents within the claim became widely apparent, those regarding themselves as having apical male neitiv ancestors did not advance their suspicions that native title may have referred only to them. It became locally understood as involving every resident possessing either male or female neitiv ancestors.

The first successful Warraber native title determination occurred on 6 July 2000 with a special local session of the Federal Court of Australia, presided over by Justice Drummond. ${ }^{15}$ At this event there were signs that many residents were tending to ignore the specific framing of the native title claim as a Warraberalgal event, while embracing the general recognition of shared emplacement it offered to the community. Residents - both neitiv and poren - have tended to refer to the event and to native title itself as affirming the earlier Gau Clan claim, rather than acting in any way to distinguish residents along lines of ancestral emphasis.

In any case, as I have described, those identifying as neitiv envisaged the descendants of foreign male ancestors (porena) to be legitimately of Warraber. They had acquired land from neitiv figures and thus belonged to Warraber. In addition, they regarded each other as kin, sharing their lives, religious practices and work interests for over a century. In this sense, Warraber thinking about the 'total condition of recognisable indigeneity' can be said to diverge from the preconceptions informing native title. But at the same time, the emergence of 'Warraberalgal' as a form of collective representation distinct from, but as encompassing as the Gau Clan, marks an instance of native title as a field of representational engagement where the ability of the Warraber community to

\footnotetext{
15 Unlike other indigenous claimants, including the Meriam, and the Yolngu (see Morphy, Chapter 2), Warraber residents were not subject to court examination and cross-examination. Their determination was reached by consent. Their first experience of court processes in this matter was at the determination hearing in 2000.
} 
maintain a commitment to their core terms of local relatedness was relatively succesful (the notion of a Warraber population that was 'ol wan pamli').

The naitiv/porena or autocthonous/non-autocthonous distinction may not be directly relevant to views concerning indigeneity among Aboriginal communities. But the wider relevance of the Warraber situation, outside the realm of native title, may simply be in reminding us of the historical part played by the European presence in shaping multiple modes of being indigenous, some of which are likely to have been as much a productive expression of indigenous/outsider interaction as they draw on extant aspects of pre-colonial lifeworlds. And that these modes may vary between specific locations, specific groups and specific sets of historical interactions (indeed, this is so even within Torres Strait itself). While certain modes are unlikely to be intuitively recognised by state-sponsored processes like native title, such processes may nevertheless play a part in continuing forms of expressing a 'total condition of indigeneity' that exceeds the expectations of the processes themselves.

\section{References}

Agamben, G. 1998. Homo Sacer: Sovereign Power and Bare Life, Stanford University Press, Stanford.

Beckett, J. 1977. 'The Torres Strait Islanders and the pearling industry: a case of internal colonialism', Aboriginal History, l (1): 77-104.

Beckett, J. 1987. Torres Strait Islanders: Custom and Colonialism, Cambridge University Press, Cambridge.

Beckett, J. 1995. 'The Murray Island land case', The Australian Journal of Anthropology, 6: 15-31.

Brennan, F. 1991. 'The Queensland Aboriginal Land Act 1991', Aboriginal Law Bulletin, 2: 10-12.

Davis, R. 1998. Epochal Bodies and Gendered Time, PhD Thesis, The Australian National University, Canberra.

Department of Premier and Cabinet 1999. Guide to Compiling a Connection Report, Native Title Services, Department of Premier and Cabinet, Brisbane.

Dodson, M. 2007. Annual Mabo Lecture extract, 7 June 2007, available at <http://www.abc.net.au/news/stories/2007/06/08/1945698.htm>. Accessed 25 August 2007.

Haddon, A. 1904 [1971]. Reports of the Cambridge Anthropological Expedition to Torres Straits, Vol. 5, Sociology, Magic and Religion of the Western Islanders, Cambridge University Press, Cambridge. 
Haddon, A. 1935 [1971]. Reports of the Cambridge Anthropological Expedition to Torres Straits, Vol. 1, General Ethnography, Cambridge University Press, Cambridge.

Hinkson, M. and Smith, B. (eds) 2005. Figuring the Intercultural in Aboriginal Australia, Special Issue, Oceania, 75 (3): 157-66.

Keen, I. 1999. 'Cultural continuity and native title claims', Land, Rights, Laws: Issues of Native Title, 1 (28): 1-8.

Kondos, V. and Cowlishaw, G. 1995. 'Introduction: conditions of possibility', The Australian Journal of Anthropology, 6 (1 \& 2): 1-14.

Lahn, J. 2003. Past Visions, Present Lives: Sociality and Locality in a Torres Strait Community, PhD Thesis, James Cook University of North Queensland, Townsville.

Lahn, J. 2004. "Living in the light" and island dance: morality and temporality in Warraber Christianities', in R. Davis (ed.), Woven Histories, Dancing Lives: Torres Strait Islander Identity, Culture and History, Aboriginal Studies Press, Canberra.

Lawrence, H. 2004. “"The great traffic in tunes": agents and musical and religious change in eastern Torres Strait', in R. Davis (ed.), Woven Histories, Dancing Lives: Torres Strait Islander Identity, Culture and History, Aboriginal Studies Press, Canberra.

Malbon, J. 1996. 'Torres Strait conference on land and sea claims', Aboriginal Law Bulletin, 3 (78): 16-18.

Merlan, F. 1995. 'The regimentation of customary practice: from Northern Territory land claims to Mabo', The Australian Journal of Anthropology, 6 (1 \& 2): 64-82.

Merlan, F. 1998. Caging the Rainbow: Places, Politics, and Aborigines in a North Australian Town, University of Hawai'i Press, Honolulu.

Morris, B. 2003. 'Anthropology and the state: the ties that bind', Social Analysis, 47 (1): 137-44.

Mullins, S. 1990. "Heathen Polynee" and "Nigger Teachers": Torres Strait and the Pacific Islander ascendancy', Aboriginal History, 14 (2): 152-67.

Mullins, S. 1995. Torres Strait: A History of Colonial Occupation and Culture Contact 1864-1897, Central Queensland University Press, Rockhampton.

Neate, G. 1997. 'Torres Strait Islander Land Act 1991', Indigenous Law Bulletin, 4 (7): 13-16.

Pearson, N. 1993. '204 years of invisible title', in M. Stephenson and S. Rathapa (eds), Mabo: A Judicial Revolution, University of Queensland Press, St. Lucia. 
Shnukal, A. 1992a. 'Pacific Islander immigrants in Torres Strait', Voices, 2 (2): 5-14.

Shnukal, A. 1992b. Pacific Islanders and Torres Strait 1860-1940', Australian Aboriginal Studies, (1): 14-27.

Shnukal, A. 1995. 'Practically White Men': Maori in Torres Strait, Aboriginal and Torres Strait Islander Unit, University of Queensland, Brisbane.

State of Queensland 2000. The Torres Strait Islander Land Act 1991: An Act Providing for the Transfer, Claim and Granting of Land as Torres Strait Islander Land, Department of Natural Resources Land Facts, Department of Natural Resources, Brisbane.

Sugimoto, H. 1983. 'Sue Island (Warraber)', in G. Oshima (ed.), Torres Kaikyo Wo Hitobito: People of the Torres Strait, Koko Shoin, Tokyo.

Weiner, J. 2000. 'The anthropology of and for native title', The Asia Pacific Journal of Anthropology, 1 (2): 124-32.

Weiner, J. 2003. 'The Law of the Land: a review article', The Australian Journal of Anthropology, 14 (1): 97-110.

Wolfe, P. 1999. Settler Colonialism and the Transformation of Anthropology: The Politics and Poetics of an Ethnographic Event, Cassell, London. 